EGU21-15929

https://doi.org/10.5194/egusphere-egu21-15929

EGU General Assembly 2021

(c) Author(s) 2021. This work is distributed under

the Creative Commons Attribution 4.0 License.

\title{
Geological mapping of carbonatites and related ores from the Oulad Dlim massif (Dakhla Province, Morocco) using remote sensing, portable X-ray fluorescence, and mineralogical data
}

\author{
cheikh elwali Malainine ${ }^{1,2}$, Otmane Raji ${ }^{1}$, Muhammad Ouabid ${ }^{1}$, Abdou Khouakhi ${ }^{3}$, Jean-Louis \\ Bodinier ${ }^{1,4}$, Fleurice Parat ${ }^{4}$, and Hicham El Messbahi ${ }^{5}$ \\ ${ }^{1}$ Mohammed VI polytechnic university, Geology and sustainable mining, Morocco (cheikh-elwali.malainine@um6p.ma) \\ ${ }^{2}$ Geosciences, Georessources and Geohazards laboratory, Cadi Ayyad University, Marrakech, Morocco \\ ${ }^{3}$ Centre for Environment and Agricultural Informatics, Cranfield University, UK \\ ${ }^{4}$ Géosciences Montpellier, Université de Montpellier-CNRS, Montpellier, France \\ ${ }^{5}$ Department of Geology, Sidi Mohamed ben Abdallah University, Taza, Morocco
}

During the last decades, carbonatites and associated rocks have received increased interest from mining companies and the scientific community. They represent a classic source of a variety of critical elements required by certain emerging technologies and industries such as niobium, rare earth elements (REE), and phosphorus. Morocco like many other countries have several Alkaline igneous complexes, however, their potential in terms of REE-P-rich carbonatites is poorly explored and needs to be investigated. This study is an attempt to develop an advanced exploration tool for the detection and mapping of these rocks using remote sensing. Preliminary investigations were focused on the Oulad Dlim massif at the western Reguibat Shield (Southeast of Dakhla province) where several carbonatite structures were reported, including Gleibat Lafhouda, Twihinate, Lamlaga, Lahjayra. Advanced Spaceborne Thermal and Reflection Radiometer (ASTER) data were used to: (i) identify and map carbonatites and associated rocks liable to contain REE-P mineralization, (ii) investigate their spectral features, and produce predictive maps. Several image processing techniques, have been performed including band ratio, color composite image, principal component analysis and minimum noise fraction. The combination of these techniques appears to more effectively detect carbonatites and associated rocks. The effectiveness of this approach was verified using field investigation, in-situ geochemical analysis with portable X-ray fluorescence, and petrography. The field data were used to train classifiers to better delineate the spatial distribution of the different lithological facies. The results are generally consistent with available geological maps indicating that this approach can be satisfactorily applied in the early stages of geological exploration. 